\title{
Comparative study with or without application of enhanced recovery after surgery protocols in patients undergoing elective cesarean section
}

\author{
Pammy Pravina, Khushbu Tewary*
}

Department of Obstetrics and Gynecology, Nalanda Medical College and Hospital, Patna, Bihar, India

Received: 24 August 2020

Accepted: 01 December 2020

\section{*Correspondence:}

Dr. Khushbu Tewary,

E-mail: tewarykhushbu77@gmail.com

Copyright: (c) the author(s), publisher and licensee Medip Academy. This is an open-access article distributed under the terms of the Creative Commons Attribution Non-Commercial License, which permits unrestricted non-commercial use, distribution, and reproduction in any medium, provided the original work is properly cited.

\begin{abstract}
Background: Concept of enhanced recovery after surgery (ERAS) has been applied in various surgical branches. Evidence regarding the necessary components of ERAS for obstetric population is limited. Therefore, objective of this study was to test the application of ERAS in patients undergoing elective caesarean section on the post-operative recovery process.

Methods: The study was conducted in the Department of Obstetrics and Gynecology, NMCH, Patna from January 2014 to December 2014. A total of 100 patients $(n=100)$ undergoing elective caesarean section were included in the study. Cases were allocated into two groups a) Study group included 60 patients $(n=60)$ and ERAS protocol was followed b) Control group included 40 patients $(n=40)$ and standard post-operative care protocol was followed. Two groups were compared with respect to recovery parameters, post-operative complications and satisfaction rates.

Results: More patients in the ERAS group were discharged on post-operative day 4 than the standard postoperative care group (90\% vs $12.5 \%$, p <0.0001). More patient in the ERAS group were significantly satisfied with the protocol compared to standard post-operative care $(77 \%$ vs $70 \%$, p<0.04). Approximately 77 percent of the patients in the ERAS group rated the satisfication score between 8-10 compared to 70 percent of the patients in control group $(\mathrm{p}<0.04)$. There was no difference between two groups with respect to recatheterization rate, readmission rate and post-discharge complaints.

Conclusions: In this study with application of ERAS protocol, we reported reduced hospital stay which may reduce financial burden of patients and healthcare facilities.
\end{abstract}

Keywords: Caesarean section, Post-operative complications, Post-operative care

\section{INTRODUCTION}

Globally caesarean delivery (CD) rates have been increasing during the last two decades. ${ }^{1}$ In India there is a slowgrowth of cesarean deliveries since the late 1980s. ${ }^{2}$ A recent survey done by National Family and Health Survey (NFHS-4) has documented the overall caesarean birth is about $17.2 \% .^{3}$ The majority of women undergoing cesarean section are young and healthy and therefore have the capacity for rapid recovery during the postoperative period.
Enhanced recovery was first described in 1997 by Wilmore and Kehlet. The concept of enhanced recovery after surgery was introduced first in colorectal surgery and now it is practiced across surgical specialties that include gynaecology, urology and orthopaedics., ${ }^{4,5}$

There is a wide variation in the components of enhanced recovery after surgery among different specialties but the principles remain same. ${ }^{6-8}$ The various components of enhanced recovery after surgery include provision of preadmission information to expectant mothers, good perioperative nutrition and hydration, minimally invasive surgical technique, efforts to maintain normothermia, 
prevention of post-operative nausea and vomiting ,effective post operative pain relief, early post operative oral intake, early removal of urinary catheter, early post operative mobilization. ${ }^{9}$

These components work in conjunction to synergize each other that reduce stress and cytokine levels, promote trauma repair, and reduce complications. ${ }^{10,11}$ The strategy of enhanced recovery (ER) for elective cesarean section would have the advantages of reduce hospital stay, heath care cost and improve patient satisfaction.

To date very little evidence is available regarding the necessary components of Enhanced recovery after surgery for the obstetric population, so further research is needed to develop and evaluate pathways for enhanced recovery in elective cesarean section.

The objective of the present study was to test the application of enhanced recovery after surgery (ERAS) in patients undergoing elective caesarean section on the post-operative recovery process.

\section{METHODS}

The study was conducted in the Department of Obstetrics and Gynecology, NMCH, Patna, Bihar, from January 2014 to December 2014. The study was approved by Institutional Ethics Committee (No:). Written informed consent was taken from all the participants prior to enrollment. A total of 100 patients $(n=100)$ undergoing elective caesarean section after satisfying the inclusion and exclusion criteria were included in the study (Table $1)$.

\section{Inclusion criteria}

25-45 years women having gestation age >38 weeks were included in the study.

\section{Exclusion criteria}

Women with prior medical illness like anemia, cardiac disease, diabetes mellitus, renal disease, obstetric complications like hypertensive disorder of pregnancy, gestational diabetes, complications during surgery like postpartum haemorrhage, bladder injury, bowel injury were excluded from the study.

The cases were allocated into two groups as follow. Patients who readily agree to accept enhanced recovery after surgery were kept under case group and control group were the patients not convinced about it.

Study group included 60 patients $(n=60)$ and enhanced recovery after surgery protocol was followed. Control group included 40 patients $(n=40)$ and standard postoperative care protocol was followed.

The protocol for enhanced recovery after surgery and standard post-operative care are mentioned in Table 1.
Table 1: Enhanced recovery after surgery and standard post-operative care.

\begin{tabular}{|c|c|c|}
\hline & $\begin{array}{l}\text { Enhanced } \\
\text { recovery after } \\
\text { surgery }\end{array}$ & $\begin{array}{l}\text { Standard post- } \\
\text { operative care }\end{array}$ \\
\hline Oral intake & $\begin{array}{l}\text { Encouragement } \\
\text { for early oral } \\
\text { intake } \\
\text { Patients were } \\
\text { given chewing } \\
\text { gums to chew } \\
\text { every two hours } \\
\text { for } 5 \text { to } 10 \text { min } \\
\text { beginning two } \\
\text { hours } \\
\text { postoperatively }\end{array}$ & $\begin{array}{l}\text { Oral intake } \\
\text { allowed after } \\
\text { passage of flatus }\end{array}$ \\
\hline $\begin{array}{l}\text { Postoperative } \\
\text { mobilization }\end{array}$ & $\begin{array}{l}\text { Early mobilization } \\
\text { preferably within } \\
6 \text { hours }\end{array}$ & $\begin{array}{l}\text { Ambulation on } \\
\text { postoperative } \\
\text { day } 1\end{array}$ \\
\hline $\begin{array}{l}\text { Removal of } \\
\text { urinary } \\
\text { catheter }\end{array}$ & $\begin{array}{l}\text { Early removal of } \\
\text { urinary catheter } \\
\text { preferably within } \\
12 \text { hours }\end{array}$ & $\begin{array}{l}\text { Removal of } \\
\text { urinary catheter } \\
\text { once patient } \\
\text { ambulated }\end{array}$ \\
\hline $\begin{array}{l}\text { Dressing of } \\
\text { wound }\end{array}$ & $\begin{array}{l}\text { Dressing of wound } \\
\text { after } 48 \text { hours }\end{array}$ & Same as ERP \\
\hline Discharge & $\begin{array}{l}\text { Discharge after } \\
\text { dressing (at } 48 \\
\text { hours) if all well* }\end{array}$ & $\begin{array}{l}\text { Discharge on day } \\
8 \text { after total stitch } \\
\text { removal, } \\
\text { however if the } \\
\text { patient is well } \\
\text { and wish early } \\
\text { discharge can } \\
\text { also be allowed } \\
\text { in this group }\end{array}$ \\
\hline
\end{tabular}

The two groups were compared with respect to various parameters like discharge day, time of first passage of flatus, time for mobilization, day 8 post discharge follow up (any complaints, wound complication, treatment satisfaction), recatheterization rate, readmission rate and patient's treatment satisfication.

Demographic data, history, examination and relevant investigations of patients were noted. Operative note were taken. Routine post-operative management was done as per hospital protocol.

Hypothermia was prevented by active warming of patients and warmed intravenous fluids. Post-operative nausea and vomiting was treated by anti-emetic agents such as ondansetron. Diclofenac or acetaminophen were used for the management of postoperative analgesia.

Participants of both the group were asked to rate the treatment satisfaction on 8th postoperative day. Patient's satisfaction was noted in terms of numerical score, 
minimum satisfaction was given a score of 0 and maximum satisfaction was given a score of 10 .

Continuous variables are presented as mean \pm SD and these variables between the two groups were compared by using Student's t-test. Categorical variables are presented as absolute numbers and percentage and these variables between the two groups were compared using Chi-squared test. The statistical analysis was done by using SPSS version 17.0. A p value $<0.05$ was considered statistical significant.

\section{RESULTS}

There was no significant difference between the two groups with respect to baseline parameters. Both the groups were comparable with respect to age, weight, gestational age, parity and blood loss during cesarean section.

Table 2: Discharge days in both groups.

\begin{tabular}{|llll|}
\hline $\begin{array}{l}\text { Discharge } \\
\text { days }\end{array}$ & $\begin{array}{l}\text { Study } \\
\text { group } \\
(\mathbf{n = 6 0 )}\end{array}$ & $\begin{array}{l}\text { Control } \\
\text { group } \\
(\mathbf{n = 4 0})\end{array}$ & P-value \\
\hline $\mathbf{4}$ & $54(90 \%)$ & $5(12.5 \%)$ & $<0.0001$ \\
\hline $\mathbf{5}$ & $5(8.33 \%)$ & $1(2.5 \%)$ & 0.1025 \\
\hline $\mathbf{6}$ & $1(1.66 \%)$ & - & \\
\hline $\mathbf{7}$ & - & - & $\begin{array}{l}\text { Comparison } \\
\text { group is not } \\
\text { present }\end{array}$ \\
\hline $\mathbf{8}$ & - & $31(77.5 \%$ & $\begin{array}{l}\text { Comparison } \\
\text { group is not } \\
\text { present }\end{array}$ \\
\hline
\end{tabular}

\section{Hospital stay}

A total of 54 cases were discharged postoperative day 4 in the study group (ERAS) while only five cases were discharged in the control group (standard perioperative care) as shown in Table 2. The difference was statistically significant $(\mathrm{p}<0.0001)$. Five patients were discharged on day 5 and 1 patient was discharged on day 6 in the study group (ERP). Thirty one cases $(77.5 \%)$ were discharged on postoperative day 8 in the control group (standard perioperative care).

\section{Time for first flatus and mobilization}

The time take for first flatus between the both the groups is depicted in Table 3. The time for first mobilization between the both the groups is depicted in Table 4 .

\section{Post-discharge complaints (Day 8)}

Total eight patients in the study group (13.33\%) complained of stitch line pain in the study group compared to 10 patients $(25 \%)$ in the control group $(\mathrm{p}=0.64)$.

The stitch line discharge was present in seven patients $(11.66 \%)$ in the study group compared to six patients $(15 \%)$ in the control group $(\mathrm{p}=0.78)$.

Table 3: Time for first passage of flatus.

\begin{tabular}{|llll|}
\hline $\begin{array}{l}\text { Time for } \\
\text { first passage } \\
\text { of flatus } \\
\text { (hours) }\end{array}$ & $\begin{array}{l}\text { Study group } \\
(\mathbf{n = 6 0 )}\end{array}$ & $\begin{array}{l}\text { Control } \\
\text { group }(\mathbf{n}=40)\end{array}$ & $\begin{array}{l}\mathbf{P} \\
\text { Value }\end{array}$ \\
\hline $\mathbf{6}$ & $6(10 \%)$ & $1(2.5 \%)$ & 0.06 \\
\hline $\mathbf{1 2}$ & $10(16.66 \%)$ & $4(10 \%)$ & 0.11 \\
\hline $\mathbf{1 8}$ & $14(23.33 \%)$ & $7(17.5 \%)$ & 0.13 \\
\hline $\mathbf{2 4}$ & $20(33.33 \%)$ & $11(27.5 \%)$ & 0.11 \\
\hline $\mathbf{3 0}$ & $7(11.66 \%)$ & $11(27.5 \%)$ & 0.34 \\
\hline $\mathbf{3 6}$ & $2(3.33 \%)$ & $2(5 \%)$ & 1 \\
\hline $\mathbf{4 2}$ & $1(1.66 \%)$ & $2(5 \%)$ & 0.5637 \\
\hline $\mathbf{4 8}$ & - & $2(5 \%)$ & - \\
\hline
\end{tabular}

Table 4: Time for first mobilization.

\begin{tabular}{|llll|}
\hline $\begin{array}{l}\text { Time for first } \\
\text { mobilization } \\
\text { (hours) }\end{array}$ & $\begin{array}{l}\text { Study group } \\
(\mathbf{n = 6 0 )}\end{array}$ & $\begin{array}{l}\text { Control } \\
\text { group } \\
(\mathbf{n = 4 0 )}\end{array}$ & P value \\
\hline $\mathbf{6}$ & $12(20 \%)$ & - & \\
\hline $\mathbf{1 2}$ & $25(41.66)$ & $5(12.5 \%)$ & 0.0003 \\
\hline $\mathbf{1 8}$ & $10(16.66)$ & $8(20 \%)$ & 0.6374 \\
\hline $\mathbf{2 4}$ & $11(18.33 \%)$ & $15(37.5 \%)$ & 0.4328 \\
\hline $\mathbf{3 0}$ & $2(3.33 \%)$ & $12(30 \%)$ & 0.0075 \\
\hline
\end{tabular}

\section{Readmission and recatherization}

Eight patients $(13.33 \%)$ in the study group were readmitted compared to seven patients $(17.5 \%)$ in the control group $(\mathrm{p}=0.06)$. Recatheterization was done in 5 patients $(8.33 \%)$ in the study group compared to 4 patients $(10 \%)$ in the control group $(\mathrm{p}=0.73)$.

\section{Patient satification (Table 5)}

Approximately 77 percent of the patients in the ERAS group rated the satisfication score between 8-10 compared to 70 percent of the patients in the control group $(\mathrm{p}<0.04)$.

Table 5: Patient satisfication score.

\begin{tabular}{|llll|}
\hline $\begin{array}{l}\text { Pt's } \\
\text { satisfaction } \\
\text { score }\end{array}$ & $\begin{array}{l}\text { Study } \\
\text { group } \\
(\mathbf{n = 6 0 )}\end{array}$ & $\begin{array}{l}\text { Control } \\
\text { group } \\
(\mathbf{n = 4 0 )}\end{array}$ & P Value \\
\hline $\mathbf{5}$ & $1(1.66 \%)$ & $2(5 \%)$ & 0.56 \\
\hline $\mathbf{5 - 8}$ & $13(21.66 \%)$ & $10(25 \%)$ & 0.53 \\
\hline $\mathbf{8 - 1 0}$ & $46(76.66 \%)$ & $28(70 \%)$ & 0.04 \\
\hline
\end{tabular}




\section{DISCUSSION}

The present study assess the effectiveness of ERAS on elective caesarean section, we found that more patients in the ERAS group were discharged on post-operative day 4 than the standard postoperative care group (90\% vs $12.5 \%, \mathrm{p}<0.0001)$. Maximum cases in the standard postoperative care group were discharged on postoperative day $8(n=31,77.5 \%)$. Various other studies have reported different findings. Baluku et al statistically significant shorter length of stay for the ERAS arm compared to standard of care in cases of emergency cesarean section, with a difference of 18.5 hours $(\mathrm{p}<0.001){ }^{12}$

Teigen et al reported that ERAS was not associated with a significantly increased rate of postoperative day 2 discharges when compared with standard care in cases of elective cesarean section. ${ }^{13}$ The difference in the findings may be due to the different ERAS protocols being followed. In the UK, the National Institute for Health and Care excellence states that women who do not have any complication during cesarean section ,are afebrile and recovering well, should be offered early discharge (after 24 hours) from hospital as it leads to decreased readmission rate. ${ }^{14}$

Compared to the control group, the ERAS group had significantly more patients who mobilized earlier at 6 hours and the difference was significant (12.5 vs 41.66 , $\mathrm{p}<0.0003)$. More patients in the ERAS group pass the first flatus compared to standard postoperative care group, however, the difference was not significant.

The incidence of complications of stitch line pain and discharge was lower in the ERAS group compared to standard postoperative group however the difference was not significant. Similarly, there was no difference between the two groups with respect to readmission and recatherization rates.

More patient in the ERAS group were significantly satisfied with the protocol compared to standard postoperative care $(77 \%$ vs $70 \%, \mathrm{p}<0.04)$. One study on early discharge in cases of cesarean delivery showed higher maternal satisfaction in the early discharge group compared to women in a routine care group. ${ }^{14}$ Two surveys conducted in UK among anesthesiologists and maternity unit supported the concept of ERAS. ${ }^{16,17}$

One major challenge in implementing the ERAS protocol in India in the illiteracy rate. ${ }^{18}$ If there is a complication, a littearte patient may not able to notice the warning sign compare to literate person. Therefore, patient education status and level of understanding should be assessed before practicing ERAS.

\section{Limitations}

First, the sample size was small this is beacsue the study was conducted as per the availability of the resources and looking into the duration available for the project. Second, we were not able to blind the subjects and investigator however utmost care was taken in reporting the data. The findings of the study should be supported by large trial in future.

In this study with application of enhanced recovery after surgery, we reported reduce hospital stay which may reduce financial burden both of the patients and healthcare facilities. This would help a mother to care for her baby much earlier without compromising her safety and satisfaction. Hospital will have advantage in terms of decreased bed occupancy and thus number of patients being treated is increased and health care resources will be efficiently used.

\section{CONCLUSION}

In this study with application of enhanced recovery after surgery, we reported reduce hospital stay which may reduce financial burden both of the patients and healthcare facilities. This would help a mother to care for her baby much earlier without compromising her safety and satisfaction. Hospital will have advantage in terms of decreased bed occupancy and thus number of patients being treated is increased and health care resources will be efficiently used.

\section{ACKNOWLEDGMENTS}

Authors would like to thank Dr. Rita Sinha, Associate Professor, Nalanda Medical College \& Hospital, Patna, (Bihar), Dr. Vishal Wahane, Mr. Manoj Kumar and Vivek for their help during the study.

\section{Funding: No funding sources \\ Conflict of interest: None declared \\ Ethical approval: Not required}

\section{REFERENCES}

1. Boerma T, Ronsmans C, Melesse DY. Global epidemiology of use of and disparities in caesarean sections. Lancet. 2018;392(10155):1341-8.

2. Ghosh S, James KS. Levels and trends in caesarean births cause for concern? Econ Polit Wkly. 2010;45 (5): $19-22$.

3. Guilmoto CZ, Dumont A. Trends, regional variations, and socioeconomic disparities in cesarean births in India, 2010-2016. JAMA Network Open. 2019;2 (3):e190526.

4. Niranjan N, Bolton T, Berry C. Enhanced recovery after surgery current trends in perioperative care. Updat Anaesth. 2010;26(1):18-23.

5. Melnyk M, Casey RG, Black P, Koupparis AJ. Enhanced recovery after surgery (ERAS) protocols: Time to change practice? J Can Urol Assoc. 2011;5(5):342-8. 
6. Nicholson A, Lowe MC, Parker J. Systematic review and meta-analysis of enhanced recovery programmes in surgical patients. Br J Surg. 2014;101(3):172-88.

7. Arsalani-Zadeh R, ElFadl D, Yassin N. Evidencebased review of enhancing postoperative recovery after breast surgery. Br J Surg. 2011;98(2):181-96.

8. Ibrahim MS, Khan MA, Nizam I. Peri-operative interventions producing better functional outcomes and enhanced recovery following total hip and knee arthroplasty: an evidence-based review. BMC Med. 2013;11:37.

9. Grocott MP, Martin DS, Mythen MG. Enhanced recovery pathways as a way to reduce surgical morbidity. Curr Opin Crit Care. 2012;18(4):385-92.

10. Kehlet H. Fast-track colorectal surgery. Lancet. 2008;371(9615):791-3.

11. Slim K, Kehlet H. Commentary: fast track surgery: the need for improved study design. Colorectal Dis. 2012;14 (8):1013-4.

12. Baluku M, Bajunirwe F, Ngonzi J, Kiwanuka J, Ttendo S. A randomized controlled trial of enhanced recovery after surgery versus standard of care recovery for emergency cesarean deliveries at Mbarara Hospital, Uganda. Anesth Analg. 2020;130 (3):769-76.

13. Teigen NC, Sahasrabudhe N, Doulaveris G, Xie X, Negassa A, Bernstein J, et al. Enhanced recovery after surgery (eras) at cesarean to reduce postoperative length of stay: a randomized controlled trial. Am J Obstet Gyn. 2020;222(4):372.

14. National institute for health and care excellence. caesarean section NICE clinical guideline 132. London: NICE;2012. Available at https://www.nice.org.uk/guidance/cg132/resources/c aesarean-section-pdf-35109507009733. Accessed on 10 July 2020.

15. Brooten D, Roncoli M, Finkler S. A randomized trial of early hospital discharge and home follow-up of women having cesarean birth. Obstet Gynecol. 1994;84(5):832-8.

16. Aluri S, Wrench IJ. Enhanced recovery from obstetric surgery: a U.K. survey of practice. Int J Obstet Anesth. 2014;23(2):157-60.

17. Coates E, Fuller G, Hind D. Enhanced recovery pathway for elective caesarean section. Int J Obstet Anesth. 2016;27:94-5.

18. Trikha A, Kaur M. Enhanced recovery after surgery in obstetric patients-Are we ready? J Obstet Anaesth Crit Care. 2020;10:1-3.

Cite this article as: Pravina $\mathrm{P}$, Tewary $\mathrm{K}$.

Comparative study with or without application of enhanced recovery after surgery protocols in patients undergoing elective cesarean section. Int J Reprod Contracept Obstet Gynecol 2021;10:173-7. 